\title{
PENGARUH SOSIALISASI, SANKSI, SISTEM E-FILING, TARIF, DAN KUALITAS PELAYANAN FISKUS TERHADAP KEPATUHAN WAJIB PAJAK
}

\author{
Neng Rosita Dewi ${ }^{1}$ Ardan Gani Asalam ${ }^{2}$
}

Article history:

Submitted: 7 April 2021

Revised: 23 Juli 2021

Accepted: 2 Agustus 2021

\section{Keywords:}

Taxpayer Compliance

Socialization;

Sanctions;

E-Filing System;

Rate;

\section{Kata Kunci:}

Kepa tuhan Wajib Pajak;

Sosia lisa si;

Sanksi;

Sistem e-filing;

Tarif;

\section{Koresponding:}

Fakultas Ekonomidan Bisnis

Telkom University, Jawa

Barat, Indonesia

nrositadewi@student.telkomun

iversity.ac.id

\section{Abstract}

In Indonesia, the largest income is through taxes to finance vario us state needs. Especially in the APBN, there is an important role that is owned by taxes, but tax revenues in the APBN in Indonesia havenot been maximized. With not maximal tax revenue in Indonesia, discipline, awareness and compliance of taxpayers is very muchneeded to comply with applicable tax obligations. The purpose of this research is to be able to see the effect of socialization, sanctions, e-filing system, tax rate and quality of tax service services on the compliance UMKMOP taxpayers. This research uses quantitative primary data techniques. The population in this research is UMKM OP taxpayers registered at (KPP) Pratama Cimahi 2020 using convenience sampling and the sample used is 100 samples. This research uses a questionnaire with a Likert scale of $1-5$ as the collection method. This research was analyzed using descriptive statistical analysis and multiple linear regression analysis. The results in this research state that the variables of socialization, sanctions and tax rate separately (partial) have a significant positive correlation on taxpayer compliance, but the variables of the e-filing system and the quality of tax services separately (partial) do not have a significant correlation with taxpayer compliance.

\begin{tabular}{|c|}
\hline Abstrak \\
\hline 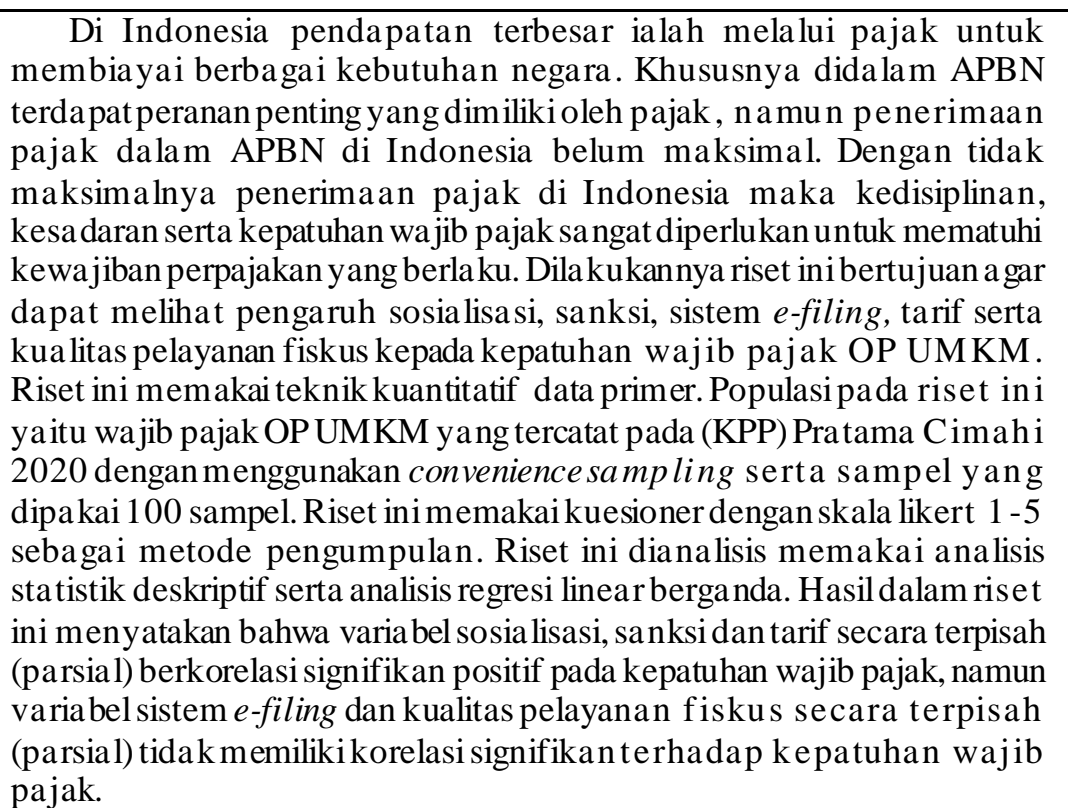 \\
\hline
\end{tabular}

\section{Abstrak} terda pat peranan penting yang dimilikioleh pajak, $n$ amun penerimaan pajak dalam APBN di Indonesia belum maksimal. Dengan tidak maksimalnya penerimaan pajak di Indonesia maka kedisiplinan, kesa daran serta kepatuhan wajib pajak sangat diperlukan untuk mematuh ewajiban perpajakan yang berla ku. Dila kukannya riset inibertujuan agar kualitas pelayanan fiskus kepada kepatuhan wajib pajak OP UMKM. Riset ini memakai teknik kuantitatif data primer. Populasi pa da riset in 1 yaju wajb pajak OPUMKM yang tercatat pada (KPP) Pratama Cimahi dipa kai 100 sampel. Riset ini memakai kuesioner dengan skala likert 1-5 sebagai metode pengumpulan. Riset ini dianalisis memakai analisis sta tistik deskriptif serta analisis regresi linear berganda. Hasil dalam riset ini menyatakan bahwa varia bel sosialisasi, sanksi dan tarif secara terpisah (parsial) berkorelasi signifikan positif pada kepatuhan wajib pajak, namun (parsial) tidak memiliki korelasi signifika nterhadap kepatuhan wajib pajak.

Fakultas Ekonomidan Bisnis Telkom University, Jawa Barat, Indonesia ${ }^{2}$ 


\section{PENDAHULUAN}

Indonesia mendapatkan pendapatan terbesar melalui pajak untuk membiayai berbagai kebutuhan negara yang tercatat pada APBN (Anggaran Pembelajaan Negara). Dengan adanya pajak dapat digunakan untuk membiayai pembangunan pemerintah pusat maupun daerah seperti mendanai pembangunan untuk fasilitas umum, mendanai anggaran pendidikan, mendanai anggaran kesehatan, dan menyediakan dana untuk kesejahteraan rakyat Indonesia. Dalam waktu lima tahun terakhir Kementrian Keuangan mencatat Penerimaan negara dari tahun 2015 sampai 2019 yang hasilnya bahwa realisasi penerimaan negara tidak melebihi target yang sudah ditetapkan oleh APBN yang dapat dilihat dari gambar 1. sebagai berikut:

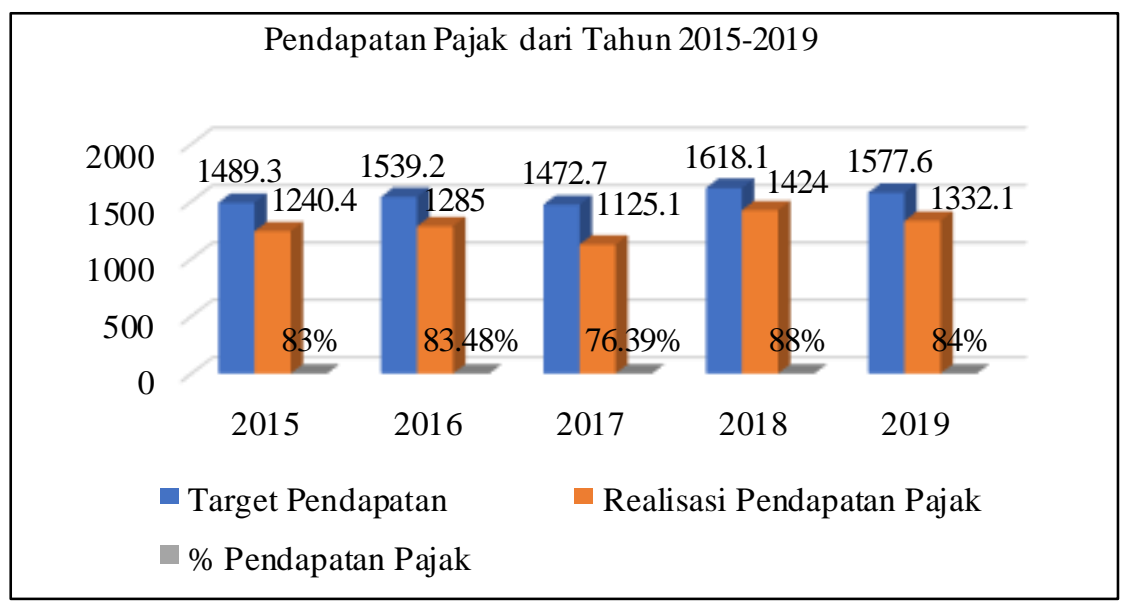

Sumber: (DetikFinance), (Liputan6), dan diolah penulis 2021

Gambar 1.

Target serta Realisasi Pendapatan dari Pajak (Milyaran Rupiah)

Maka jika dilihat dari Gambar 1. realisasi penerimaan pajak dari tahun 2015-2019 masih belum konsisten dan tidak melebihi target yang sudah ditetapkan, dengan itu Direktorat Jenderal Pajak perlu berusaha untuk meningkatkan dan mempertahankan angka realisasi penerimaan pajak agar disetiap tahunnya tetap naik dan juga konsisten untuk mencapai tujuan yang ditentukan didalam APBN. Dengan tidak konsistennya pendapatan dari pajak di Indonesia maka kedisiplinan, kesadaran serta kepatuhan untuk menaati keharusan dalam membayar perpajakan yang berlaku dibutuhkan. Kepatuhan wajib pajak ialah salah satu hal yang bisa merealisasikan target penerimaan pajak. Jika tingkat kepatuhan WP tinggi, maka begitu pula sebaliknya penerimaan pajak akan meningkat.

Sektor UMKM saat ini menjadi sumber ekonomi di Indonesia, hal tersebut tercatat dalam keikutsertaan para UMKM terhadap PDB (Produk Domestik Bruto) yang tercantum sebesar 65\% melalui penerimaan pajak PPh Final UMKM. Maka dari itu untuk meningkatkan penerimaan pajak UMKM menjadi salah satu fokus kerja bagi Kementrian Keuangan dan untuk mencapai salah satu tujuan tersebut kementrian keuangan membuat pemetaan perpajakan yang memudahkan bagi wajib pajak UMKM (kemenkeu.go.id). Upaya dalam peningkatan Kepatuhan Wajib Pajak bagi UMKM yaitu pemerintah yang telah membuat PP No 23 Tahun 2018 ialah melakukan penurunan tarif UMKM pada penghasilan semula senilai $1 \%$ menjadi $0.5 \%$, dengan adanya perubahan peraturan ini yang bertujuan agar membuat Wajib Pajak UMKM untuk semakin berpatisipasi dan lebih memudahkan wajib pajak dengan melakukan kewajiban perpajakannya.

Pengaruh Sosialisasi, Sanksi, Sistem E-Filing, Tarif Dan Kualitas Pelayanan Fiskus Terhadap Kepatuhan Wajib 
Objek dalam penelitian ini ialah KPP Pratama Cimahi dan wajib pajak OP UMKM sebagai populasi pada riset ini. Tingkat kepatuhan UMKM atau wajib pajak OP pada (KPP) Pratama Cimahi tergolong rendah. Berdasarkan jumlah UMKM yang terdaftar serta jumlah UMKM yang mela porkan SPT menyatakan tingkat kepatuhan UMKM belum mencapai target. Berikut target dan realisasi Wajib Pajak OP UMKM (KPP) Pratama Cimahi yang melaporkan SPT pada Gambar 2.:

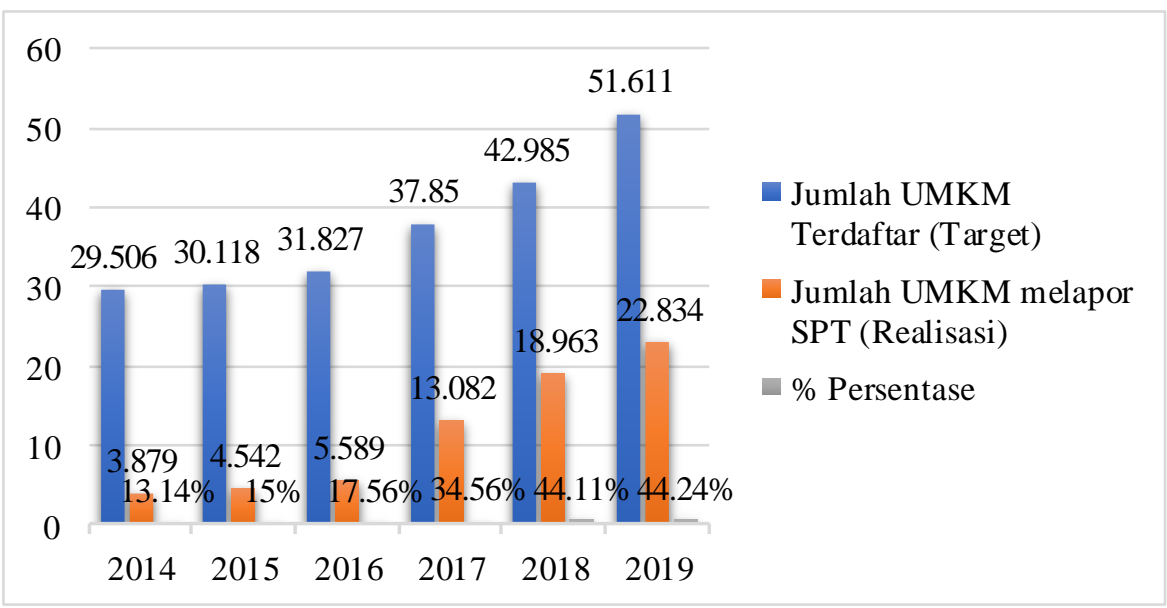

Sumber: (KPP) Pra tama Cimahi dan diolah penulis (2021)

\section{Gambar 2.}

\section{Jumlah UMKM Terdaftar serta Jumlah UMKM dalam Melaporkan SPT}

Pada Gambar 2. dapat dilihat pada (KPP) Pratama Cimahi Jumlah UMKM yang terdaftar setiap tahunnya meningkat, namun jumlah UMKM yang melaporkan SPT masih belum melebihi target yang telah ditentukan dan realisasi Wajib Pajak UMKM masih jauh dengan target walaupun jumlah Wajib Pajak yang melapor SPT juga setiap tahunnya meningkat.

Untuk mempengaruhi kepatuhan wajib pajak bagi UMKM terdapat beberapa faktor diantaranya ialah sosialisasi perpajakan, sanksi perpajakan, sistem $e$-filing, tarif pajak, dan kualitas pelayanan fiskus. Berdasarkan beberapa hasil penelitian-penelitian terdahulu terdapat perbedaan pada hal-hal yang dapat memengaruhi kepatuhan bagi WP Orang Pribadi UMKM baik itu secara bersamaan (simultan) maupun secara terpisah (parsial).

Faktor yang bisa memengaruhi kepatuhan ialah sosialisasi perpajakan, dengan adanya sosialisasi yang termasuk dalam program yang dipakai oleh DJP agar meningkatkan pemahaman serta pengetahuan masyarakat. Untuk mengukur sosialisasi perpajakan ialah dengan menggunakan indikator menurut Suryadi \& Imam (2016) ialah penyuluhan, penyelenggraan dan cara sosialisasi. Kepatuhan WP dapat meningkat dengan dilakukannya sosialisasi serta diharapkan membuat WP dapat memahami serta menyadari pentingnya perpajakan untuk mendanai berbagai kebutuhan Negara Indonesia. Riset tersebut didukung penelitian Samadiartha \& Darma (2017) serta penelitian Agustini \& Widhiyani (2019) yang menyatakan sosialisasi memiliki pengaruh positif kepada Kepatuhan WP.

Selain itu, sanksi perpajakan dapat meningkatkan kepatuhan. Menurut Mardiasmo (2018: 62), sanksi perpajakan secara tidak langsung agar mematuhi, atau memastikan dipatuhinya peraturan perundang-undangan yang berkaitan dengan norma perpajakan. Sanksi pajak bisa memengaruhi kepatuhan WP karena kekokohan sanksi perpajakan untuk memperkuat disiplin kewajiban perpajakan. Sanksi perpajakan dimaksudkan untuk mencegah kesalahan dan kecurangan. Riset tersebut telah dilaksanakan oleh Intan et al., (2020) dan penelitian Alfarisi dan Mahpudin (2020) memaparkan sanksi pajak berkorelasi positif kepada Kepatuhan WP.

$\overline{\text { Pengaruh Sosialisasi, Sanksi, Sistem E-Filing, Tarif Dan Kualitas Pelayanan Fiskus Terhadap Kepatuhan Wajib }}$ 
Selain itu, Sistem e-Filing dapat memengaruhi Kepatuhan bagi WP. E-Filing merupakan cara Wajib Pajak OP mengirimkan Surat Pemberitahuan (SPT) menggunakan saluran komunikasi internet dengan real-time serta online melewati website, atau secara elektronik mengirimkan SPTy (Surat Pemberitahuan Tahunan) (Pajak.go.id). Karena adanya $e$-Filing dapat memfasilitasi wajib pajak untuk mengajukan SPT pajak mereka menggunakan komunikasi Internet online, maka sistem $e$-filing dapat mempengaruhi kepatuhan WP. Riset tersebut telah dilaksanakan oleh Amalia (2018) dan riset yang dilaksanakan Kusmeilia (2019) memaparkan sistem e-Filing mempunyai korelasi positif signifikan kepada Kepatuhan WP.

Selain e-filing tarif pajak juga dapat memengaruhi Kepatuhan. Menurut Hidayat dan Purwana (2017) tarif pajak ialah pungutan yang memerlukan penentuan terlebih dahulu jumlah kewajiban pajak yang ditanggung oleh orang pribadi ataupun badan sebagai acuan dalam menentukan kewajiban perpajakannya agar sesuai serta adil, dengan terlebih dahulu menentukan jenis tarif yang digunakan dan persentase tarif pajak. Karena tarif pajak sepadan dengan kemampuan wajib pajak yang ada, jika tarif pajak didasarkan pada penghasilan yang sesuai, maka tarif pajak dapat memengaruhi kepatuhan pada kewajiban perpajakannya. Hal tersebut didukung oleh penelitian Maharini (2019) dan riset yang dilaksanakan Raharjo (2020) memaparkan sistem tarif pajak mempunyai korelasi positif signifikan kepada Kepatuhan WP.

Dan Kualitas Pelayanan Fiskus dapat memengaruhi Kepatuhan bagi WP. Menurut Subarkah \& Dewi (2017) pelayanan fiskus termasuk kedalam pelayanan publik, dikarenakan dioperasikan dengan lembaga pemerintah yang tidak berorientasi profit untuk tujuan penegakan hukum dan kebutuhan masyarakat. Pelayanan fiskus bisa memengaruhi kepatuhan dikarenakan wajib pajak cenderung membayar kewajiban perpajakannya ketika kualitas pelayanan yang diberikan oleh kantor pajak baik. Riset tersebut telah dilaksanakan oleh oleh Susanti \& Suhono (2020) dan riset oleh Erlina, Ratnawati, \& Andreas (2018) memaparkan sistem kualitas pelayanan fiskus mempunyai korelasi positif kepada Kepatuhan WP.

Berdasarkan kajian teori serta pengembangan hipotesis dalam penelitian ini, maka peneliti mendapatkan kerangka pemikiran pada riset ini seperti pada Gambar 3. :

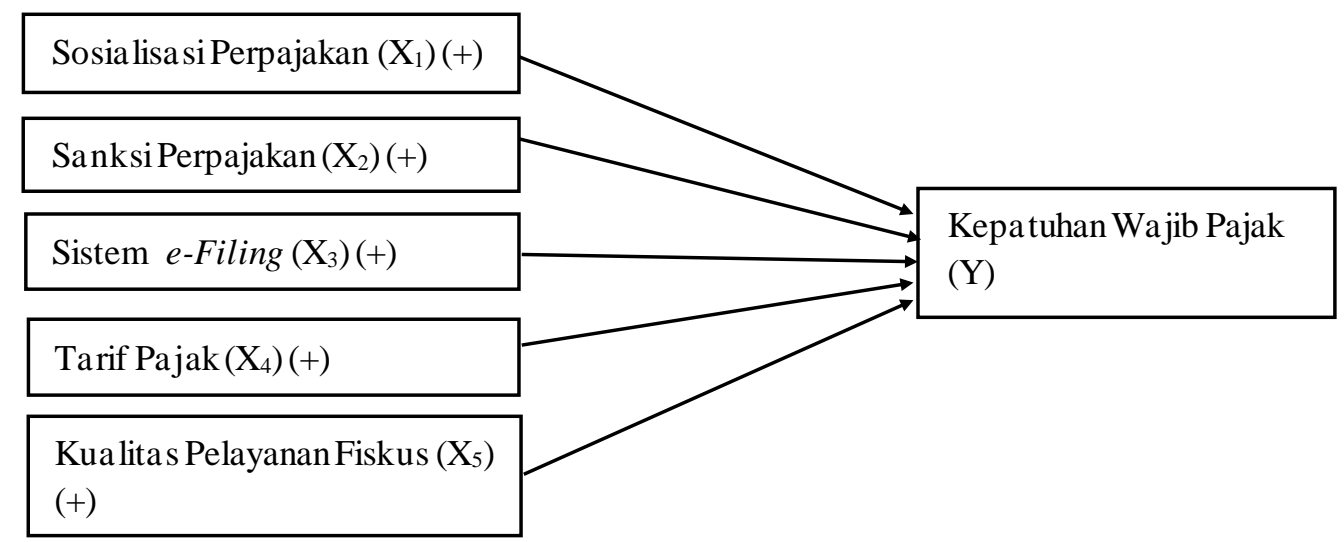

Sumber: Ola han penulis (2021)

Gambar 3.

Kerangka Pemikiran

Keterangan :

: Secara Parsial

$\overline{\text { Pengaruh Sosialisasi, Sanksi, Sistem E-Filing, Tarif Dan Kualitas Pelayanan Fiskus Terhadap Kepatuhan Wajib }}$ Pajak, 


\section{METODE PENELITIAN}

Metode penelitian yang dipakai pada riset kali ini ialah memakai metode kuantitatif serta teknik pengumpulan data yang dipakai ialah memakai kuesioner dengan perhitungan skala likert. Riset ini memakai teknik analisis statistik deskriptif serta dilakukan analisis dengan memakai analisis regresi linear berganda. Populasi pada riset ini memakai wajib pajak OP UMKM yang tercatat pada KPP Pratama Cimahi tahun 2020 memakai convenience sampling serta sampel yang dipakai sebanyak 100 sampel.

Riset ini memakai teknik analisis statistik deskriptif serta dilakukan analisis dengan memakai analisis regresi linear berganda dengan memakai sebagai berikut:

$$
\mathrm{KWP}=\mathrm{a}+\beta_{1} \mathrm{SP}_{1}+\beta_{2} \mathrm{SaP}_{2}+\beta_{3} \mathrm{SF}_{3}+\beta_{4} \mathrm{TP}_{4}+\beta_{5} \mathrm{KP}_{5}+\mathrm{e}
$$

Keterangan:

$$
\begin{aligned}
& \text { KWP = Kepatuhan Wajib Pajak } \\
& \mathrm{a} \quad=\text { Konstanta } \\
& \beta_{1} \beta_{2} \beta_{3} \beta_{4} \beta_{5} \quad=\text { Koefisien Regresi } \\
& \text { SP } \quad=\text { Sosialisasi Perpajakan } \\
& \mathrm{SaP} \quad=\text { Sanksi Perpajakan } \\
& \mathrm{SF} \quad=\text { Sistem } e \text {-Filing } \\
& \mathrm{TP} \quad=\text { Tarif Pajak } \\
& \text { KP } \quad=\text { Kualitas Pelayanan Fiskus } \\
& \text { e = Kesalahan Regresi/ error }
\end{aligned}
$$

Dalam penelitian ini peneliti melakukan perhitungan secara statistik dengan memakai bantuan SPSS 25 .

\section{HASIL DAN PEMBAHASAN}

Hasil pengumpulan data dari kuesioner diuji dan dianalisis memakai analisis deskriptif, serta memakai analisis regresi linier berganda sebagai pengujiannya. Hasil pengambilan data dari kuesioner diuji serta dilakukan analisis memakai analisis deskriptif serta pengujian hipotesis memakai analisis regresi linier berganda. Dapat dinyatakan hasil analisis deskriptif agar memberikan gambaran mengenai latar belakang dan karakteristik responden. Data responden tersebut berisikan data-data responden yang dibutuhkan oleh penelitian seperti jenis kelamin, usia, pendidikan terakhir, jenis usaha, serta berapa lama usaha responden tersebut.

Berdasarkan karakteristik responden jenis kelamin terdapat hasil pada jenis kelamin lakilaki memiliki hasil senilai $56 \%$. Di sisi lain, $44 \%$ responden adalah perempuan. Berdasarkan karakteristik umur responden menunjukkan bahwa mayoritas responden UMKM adalah wajib pajak orang pribadi berusia 31-40 tahun terdapat $57 \%$ atau 57 responden. Berdasarkan karakteristik melalui pendidikan terakhir, mayoritas responden adalah wajib pajak orang pribadi SMA/Sederajat terdapat $82 \%$ atau 82 responden terindikasi. Berdasarkan karakteristik responden menurut jenis usaha menunjukkan bahwa mayoritas responden UMKM adalah Wajib Pajak OP pada bidang kuliner/makanan sebesar 40\% maupun sebanyak 40 responden. Berdasarkan karakteristik responden berdasarkan lama usaha, mayoritas responden UMKM menunjukkan hasil dengan persentase 55\% atau 55 responden dengan lama usaha 5-10 tahun.

Pengaruh Sosialisasi, Sanksi, Sistem E-Filing, Tarif Dan Kualitas Pelayanan Fiskus Terhadap Kepatuhan Wajib 
Dalam analisis statistik deskriptif pada variabel Sosialisasi Perpajakan $\left(\mathrm{X}_{1}\right)$ memiliki hasil rata-rata dari total skor sebesar $76 \%$. Sehingga seluruh pernyataan sosialisasi perpajakan berada pada tergolong baik. Hal ini menunjukkan bahwa partisipasi dalam kegiatan sosialisasi perpajakan responden UMKM (KPP) Pratama Cimahi atau wajib pajak orang pribadi sangat tinggi.

Dalam analisis statistik deskriptif pada variabel Sanksi Perpajakan $\left(\mathrm{X}_{2}\right)$ memiliki hasil ratarata dari total skor sebesar $79,7 \%$. Sehingga seluruh pernyataan sanksi perpajakan berada pada tergolong baik. Oleh karena itu dapat dinyatakan bahwa responden memberikan pendapat sanksi pajak telah dilakukan dengan baik karena Wajib Pajak dapat memahami sanksi-sanksi perpajakan.

Rata-rata total skor dalam analisis statistik deskriptif variabel Sistem e-Filing (X3) ialah 80,16\%. Oleh karena itu, pada UMKM Kantor Pelayanan Pajak (KPP) Pratama Cimahi dapat dinyatakan penerapan sistem $e$-Filing pada wajib pajak OP termasuk tergolong baik. Adanya $e$-Filing karena tidak perlu menyerahkan dokumen kecuali wajib pajak diminta untuk mengirimkan pada kantor pajak, serta dapat mempermudah dalam membayar kewajiban kapan saja, di mana saja.

Dalam analisis statistik deskriptif pada variabel Tarif Pajak $\left(\mathrm{X}_{4}\right)$ menunjukkan rata-rata dari total skor sebesar 83\%. Sehingga seluruh pernyataan tarif pajak berada pada tergolong baik. Oleh karena itu, sebagian besar responden dapat menyimpulkan bahwa tarif pajak UMKM sebesar 0.5\% membuat UMKM patuh terhadap membayar pajak.

Analisis statistik deskriptif terhadap Kualitas Pelayanan Fiskus $\left(\mathrm{X}_{5}\right)$ menunjukkan rata-rata skor keseluruhan sebesar 78,1\%. Oleh karena itu kualitas pelayanan Fiskus (KPP) Pratama Cimahi tergolong baik, karena telah memberikan pelayanan yang profesional dan memperhatikan segala keluhan yang dirasai Wajib Pajak serta membuat penyelesaian kepada Wajib Pajak.

Pada analisis statistik deskriptif pada variabel Kepatuhan Wajib Pajak (Y) menunjukkan ratarata dari total nilai sebesar 78.1\%. Dapat disimpulkan bahwa Kepatuhan WP pada wajib pajak OP pada UMKM pada Kantor Pelayanan Pajak (KPP) Pratama Cimahi berada dalam kategori baik.

Tabel 1.

Uji Normalitas

\begin{tabular}{llr}
\hline & & Unstandardized Residual \\
$\mathrm{N}$ & & 100 \\
\hline NormalParameter & Mean &, 0000000 \\
& Std. Deviation & 2,96776654 \\
Most ExtremeDifferences & Absolute &, 063 \\
& Positive & 063 \\
& Negative &,- 051 \\
Test Statistic & &, 063 \\
Asymp Sig. (2-tailed) & &, $200^{\text {c.d }}$ \\
\hline
\end{tabular}

Sumber: SPSS 25 da ta diolah oleh penulis (2021)

Hasil dari tabel 1. dapat dilihat pada hasil uji normalitas yang memakai metode nonparametrik One-sample (K-S) mempunyai nilai Sig diatas dari 0.05 yang memiliki nilai 0.200 , berarti hasil uji normalitas terdistribusi dengan normal.

$\overline{\text { Pengaruh Sosialisasi, Sanksi, Sistem E-Filing, Tarif Dan Kualitas Pelayanan Fiskus Terhadap Kepatuhan Wajib }}$ 
Tabel 2.

Uji Multikolinearitas

\begin{tabular}{lccc}
\hline & Model & \multicolumn{2}{c}{ Collinearity Statistics } \\
& & Tolerance & VIF \\
\hline & (Constant) & .613 & 1.631 \\
SP & & .462 & 2.166 \\
SaP & & .687 & 1.455 \\
SF & .581 & 1.722 \\
TP & KP & .659 & 1.517 \\
\hline
\end{tabular}

Sumber: SPSS 25 da ta diolah oleh penulis (2021)

Hasil dari Tabel 2. yang merupakan hasil dari pengujian multikolinieritas menunjukkan nilai tolerance pada masing-masing variabel diatas 0.10, serta nilai VIF (Variance Inflation Factors) dari masing-masing variabel dibawah 10 , berarti hasil uji multikoliaritas menunjukkan tidak berkorelasi atau terjadinya multikolinearitas pada masing-masing variabel yang dipakai pada riset kali ini.

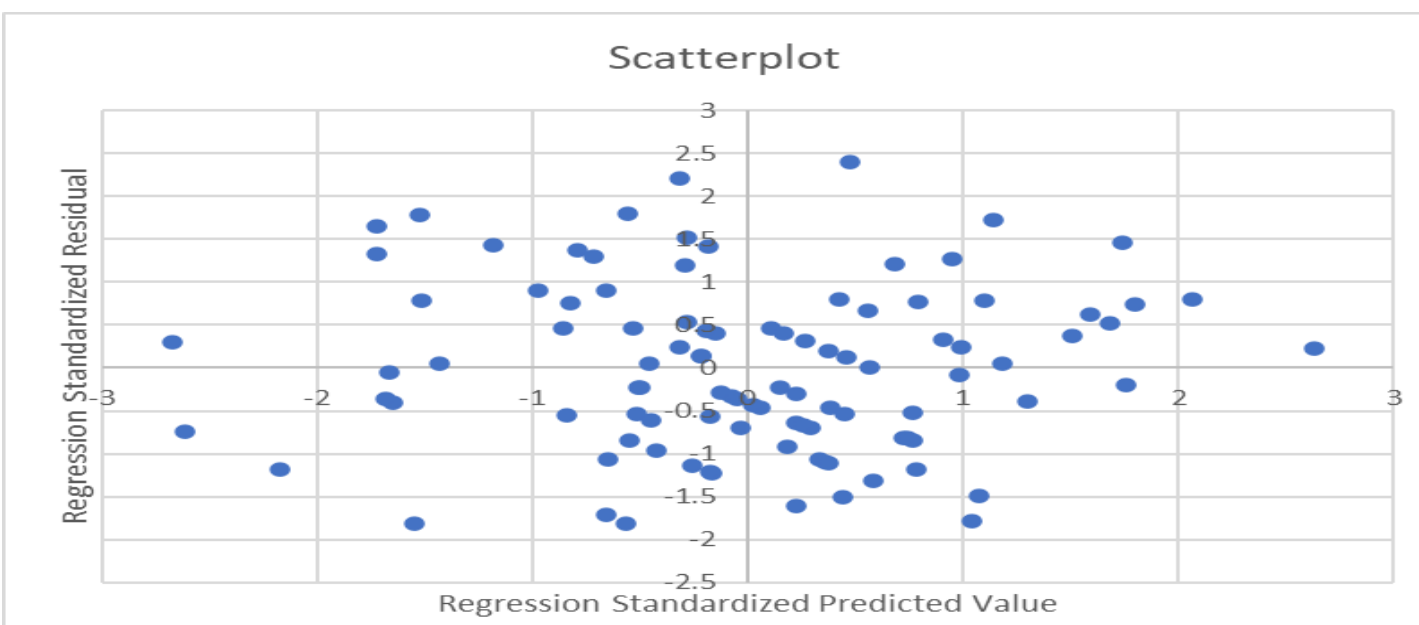

Sumber: SPSS 25 da ta diolah oleh penulis (2021)

Gambar 4.

Uji Heteroskedastisitas

Hasil dari Gambar 4. dapat dilihat pada grafik scatterplot bahwa tidak terbentuknya suatu pola dalam grafik tersebut dikarenakan data menyebar secara acak, berarti dalam hasil riset ini tidak terdapat heteroskedastisitas.

Tabel 3.

Uji F (Simultan)

\begin{tabular}{lrrrrr}
\hline Model & Sum of Squares & df & Mean Square & F & Sig. \\
\hline Regression & 926.284 & 5 & 185.257 & 19.971 & $.000^{\mathrm{b}}$ \\
Residual & 871.956 & 94 & 9.276 & & \\
Total & 1798.240 & 99 & & &
\end{tabular}

Sumber: SPSS 25 da ta diolah oleh penulis (2021)

Pengaruh Sosialisasi, Sanksi, Sistem E-Filing, Tarif Dan Kualitas Pelayanan Fiskus Terhadap Kepatuhan Wajib 
Tabel 4.

Uji Koefisien Determinasi

\begin{tabular}{lcccc}
\hline Model. & $\mathrm{R}$ & $\begin{array}{c}\mathrm{R} \\
\text { Square }\end{array}$ & Adjusted R Square & Std.Error \\
\hline 1 & $.718^{\mathrm{a}}$ & .515 & .489 & 3.046 \\
\hline \multicolumn{4}{c}{ Source $:$ SPSS 25 data diolah oleh penulis (2021) }
\end{tabular}

Hasil dari Tabel 3. memaparkan bahwa pada uji simultan memiliki nilai signifikan senilai $.000<0,05$, serta pada Tabel 4. memaparkan bahwa koefisien determinasi mempunyai hasil Adjusted $R$ Square senilai 0.489 atau senilai $48.9 \%$. Hal tersebut menunjukkan bahwa variabel dependen memiliki pengaruh senilai $48.9 \%$ oleh variabel sosialisasi, sanksi, sistem e-filing, tarif pajak dan kualitas pelayanan fiskus. Sedangkan $51.1 \%$ dimiliki masing-masing variabel yang tidak tercantum pada riset ini.

Tabel 5.

Uji T (Parsial)

\begin{tabular}{lcccccc}
\hline & \multicolumn{2}{c}{$\begin{array}{c}\text { Unstandardized } \\
\text { Coefficients }\end{array}$} & $\begin{array}{c}\text { Standardized } \\
\text { Coefficients }\end{array}$ & t & Sig \\
\cline { 2 - 5 } & Model & $\mathrm{B}$ & Std.Error & $\mathrm{B}$ & & \\
\hline (Constant) & & & & & \\
SP & 13.323 & 4.109 & & 3.242 & .002 \\
SaP & .200 & .090 & .203 & 2.215 & .029 \\
SF & .598 & .185 & .341 & 3.230 & .002 \\
TP & .087 & .070 & .107 & 1.238 & .219 \\
KP & 381 & .153 & .235 & 2.493 & .014 \\
\hline
\end{tabular}

Sumber : SPSS 25 da ta diolah oleh penulis (2021)

Hasil dari Tabel 5. pada hasil uji parsial variabel $\mathrm{X}_{1}$ (Sosialisasi Perpajakan) mempunyai hasil koefisien regresi senilai 0,200 dengan memiliki nilai signifikansinya senilai $0,029<0.05$ berarti variabel sosialisasi berkorelasi positif kepada kepatuhan WP. Hasil riset sesuai dengan hipotesis dan mendukung penelitian Samadiartha \& Darma (2017) dan penelitian Agustini \& Widhiyani (2019) bahwa sosialisasi pajak berkorelasi positif kepada kepatuhan wajib pajak.

Pada variabel $\mathrm{X}_{2}$ (Sanksi Perpajakan) mempunyai hasil koefisien regresi senilai 0,598 yang menghasilkan nilai signifikannya senilai $0,002<0,05$, berarti variabel sanksi pajak berkorelasi positif kepada kepatuhan wajib pajak. Temuan riset ini sesuai pada hipotesis dan mendukung riset Ngadiman dan Huslin (2017) serta riset Intan et al., (2020) memaparkan sanksi pajak memiliki pengaruh positif kepada kepatuhan wajib pajak.

Pada variabel $\mathrm{X}_{3}$ (Sistem e-Filing) memiliki hasil koefisien regresi sebanyak 0,087 yang menghasilkan nilai signifikannya senilai $0.219>0.05$, yang berarti variabel $\mathrm{X}_{3}$ berkorelasi positif namun dalam uji parsial tidak memiliki korelasi kepada kepatuhan wajib pajak. Temuan riset ini tidak sesuai pada hipotesis, tetapi hasil pada riset ini didukung oleh Solekhah dan Supriono (2018) dan riset Rina et al., (2020) memaparkan bahwa sistem e-Filling tidak mempunyai pengaruh kepada kepatuhan wajib pajak.

Pada variabel $\mathrm{X}_{4}$ (Tarif Pajak) mempunyai hasil koefisen regresi senilai 0,381 yang menghasilkan nilai signifikannya senilai $0.014<0.05$, berarti variabel mengenai tarif pajak mempunyai pengaruh positif kepada kepatuhan WP. Riset ini sesuai dengan hipotesis dan mendukung

Pengaruh Sosialisasi, Sanksi, Sistem E-Filing, Tarif Dan Kualitas Pelayanan Fiskus Terhadap Kepatuhan Wajib 
riset Maharini (2019) dan riset yang dilakukan Raharjo et al., (2020) memaparkan tarif pajak mempunyai pengaruh positif kepada kepatuhan wajib pajak.

Pada variabel $\mathrm{X}_{5}$ (Kualitas Pelayanan Fiskus) memiliki hasil koefisien regresi senilai -0,003 yang menghasilkan nilai signifikannya senilai $0,973>0,05$, yang berarti variabel mengenai Kualitas Pelayanan Fiskus memiliki pengaruh negatif dan secara terpisah (parsial) tidak memiliki korelasi kepada Kepatuhan Wajib Pajak. Riset ini tidak sesuai pada hipotesis, namun riset ini didukung oleh penelitian Maharini (2019) dan penelitian Ayu \& Sari (2017) memaparkan kualitas pelayanan fiskus tidak mempunyai pengaruh kepada kepatuhan wajib pajak.

\section{SIMPULAN DAN SARAN}

Berdasarkan dengan hasil riset kali ini dapat dinyatakan variabel Sosialisasi, Sanksi, Tarif berkorelasi positif signifikan kepada Kepatuhan Wajib Pajak OP UMKM pada KPP Pratama Cimahi, namun pada variabel Sistem $e$-Filing serta variabel Kualitas Pelayanan Fiskus tidak memiliki korelasi kepada Kepatuhan Wajib Pajak OP UMKM pada KPP Pratama Cimahi.

Berdasarkan kesimpulan riset yang telah dipaparkan, penulis memiliki saran bagi KPP Pratama Cimahi agar mempertahankan atau memperluas variabel yang berpengaruh, dan yang tidak berpengaruh harus menjadi catatan bagi KPP Pratama Cimahi seperti mengadakan sosialisasi dalam penggunaan sistem $e$-filing agar bisa memberikan pengetahuan dalam penggunaan sistem $e$-filing bagi wajib pajak atau masyarakat hal ini agar WP dapat meningkat dalam membayar kewajiban perpajakannya, serta dapat meningkatkan kualitas pelayanan petugas pajak kepada wajib pajak karena kualitas pelayanan merupakan suatu faktor yang bisa memengaruhi kepatuhan wajib pajak. Untuk peneliti selanjutnya disarankan meneliti Wajib Pajak OP UMKM sesuai pada Peraturan Pemerintah No. 23 Tahun 2018 dengan objek Kantor Pelayanan Pajak Pratama yang berbeda, serta dapat menambahkan atau menggunakan variabel yang belum digunakan dalam riset ini seperti sistem $e$ Biling serta pemahaman perpajakan.

\section{REFERENSI}

Agustini, K. D., \& Widhiyani, N. L. S. (2019). Pengaruh PenerapanE-Filing, Sosialis a si Perpa jakan, Sanksi Perpajakan Terhadap Kepatuhan Wajib Pajak Orang Pribadi. E-Jurnal Akuntansi, 27 (2), 1343 - 1364 https://doi.org/10.24843/eja.2019.v27.i02.p19

Alfa risi, G. D., \& Mahpudin, E. (2020). Pengaruh Penerapan E-Spt, Kesadaran Wajib Pajak Dan Kpp Pra tama Ka ra wang Utara. E-Jurnal Ekonomi Dan Bisnis Universitas Udayana, 10(9), 969-994.

Amalia, A. R. (2018). Pengaruh Implementasi E-Filling, Pengetahuan Perpajakan, Da n Sa nksi Perpajakan Terhadap Kepatuhan Wajib Pajak Orang Pribadi Pa da Pelaporan Surat Pemberitahuan (Studi Ka sus pada Kantor Dinas Pendidikan dan Kebudayaan Kabupaten Tegal). E-Proceeding of Management, 59(2), 5164 5165.

Ayu, V., \& Sari, P. (2017). Pengaruh Tax Amnesty, Pengetahuan Perpajakan, dan Pelayanan Fiskus Terhadap Kepatuhan Wajib Pajak Sekolah Tinggi Ilmu Ekonomi Indonesia (STIESIA) Surabaya. Jurnal Ilmu Dan Riset Akuntansi, 6, 744-760.

Intan, M., Syafitri, D., \& Rosharlianti, Z. (2020). Peran Whistle Blowing Sy stem Dalam Memoderasi Penerapan E-Filling Dan Sanksi Perpajakan Terhadap Kepatuhan Wajib Pajak. Nominal: Barometer Riset Akuntansi Dan Manajemen, 9(2), 48-61.

Kusmeilia, R. R. (2019). Pengaruh Pengetahuan Perpajakan, Penerapan Sistem E-Filing dan Penerapan Sistem E-Billing Terhadap Kepatuhan Wajib Pajak. Jurnal Akuntansi, AuditDan Sistem Informasi Akuntansi, 3(3), 364-379.

Ma harini, S. (2019). Pengaruh Sosialisa si Perpa jakan, Kualitas Pelayanan Perpajakan, Tarif Pajak dan Ketegasan Sanksi Perpajakan. E-Proceeding of Management, 6(2), 3593-3601.

Pajak.go.id. (n.d.). Electronic Filing Direktorat Jenderal Pajak. Retrieved January 9, 2021, from https://www.pajak.go.id/id/electronic-filing

Raharjo, N. K., Majidah, M., \& Kurnia, K. (2020). Pengaruh Pemahaman Peraturan Perpajakan, Tarif Pajak, dan

Pengaruh Sosialisasi, Sanksi, Sistem E-Filing, Tarif Dan Kualitas Pelayanan Fiskus Terhadap Kepatuhan Wajib 
Kualitas Pelayanan Terhadap Kepatuhan Wajib Pajak (Studi Ka sus pada Wajib Pajak Orang Priba di Non Ka rya wan di KPP Pra tamaCibinong Periode 2020). E-Jurnal Ekonomi Dan Bisnis Universitas Uda yana, 6(7), 671-686.https://doi.org/10.24843/eeb.2020.v09.i07.p05

Rina, R. N., Hermansyah, I., \& Ridlo, A. (2020). Pengaruh Fasilitas E-SPT danE-Filing Dala m Penya mpaian Surat Pemberitahuan (SPT) Terhadap Kepatuhan Wajib Pajak Badan (Survei Pa da Wa jib Pajak Badan Yang Terdaftar di KPP Pratama Kota Tasikmalaya). JurnalAkuntansi, 15(1), 28-35.

Samadiartha, I.N. D., \& Darma, G. S. (2017). Dampak Sistem E-Filing, Pengetahuan Perpajakan, So sialisa si Perpajakan, Kesadaran Wajib Pajak terhadap Kepatuhan Wajib Pajak. Jurnal Manajemen Dan Bisnis, 53(9), 1689-1699.

Solekhah, P., \& Supriono, S. (2018). Pengaruh Penerapan Sistem E-Filing, Pema haman Perpajakan, Ke sadaran Wajib Pajak dan Sanksi Perpajakan Terhadap Kepatuhan Wajib Pajak Orang Priba di di KPP Pra tama Purworejo. Journal of Economic, Management, Accounting and Technology, 1(1), 74-90. https://doi.org/10.32500/jematech.v1i1.214

Subarkah, J., \& Dewi, M. W. (2017). Pengaruh Pemahaman, Kesadaran, Kualitas Pela ya nan, Da n Ketegasan Sanksi Terhadap Kepatuhan Wajib Pajak Orang Pribadi di KPP PratamaSukoharjo. Jurnal Akuntansi Dan Pajak, 17(02). 1-10.https://doi.org/10.29040/jap.v17i02.210

Surya di, \& Imam. (2016). Pengaruh Sosialisa si Perpajakan, Sanksi Administrasi Dan Tingkat Pemahaman Wajib Pajak Terhadap TingkatKepatuhan Wajib Pajak Orang Pribadi Dalam Memenuhi Kewa jiban nya (Studi PPh Pasal 21 pada KPP Pratama Singsosari). Jurnal Mahasiswa Perpajakan, 8(1). 1-10. http://perpajakan.studentjournal.ub.ac.id/index.php/perpajakan/article/view/223

Susanti, Y., \& Suhono. (2020). Pengaruh Kualitas Pela yanan Fiskus dan Sanksi Perpajakan terhadap Kepatuhan Wajib Pajak Orang Pribadi di KPP Pratama Karawang Utara. E-Jurnal Ekonomi Dan Bisnis Universitas Udayana, 11(1), 1083-1102. 